\title{
Behavioural Economics and Policy Design
}

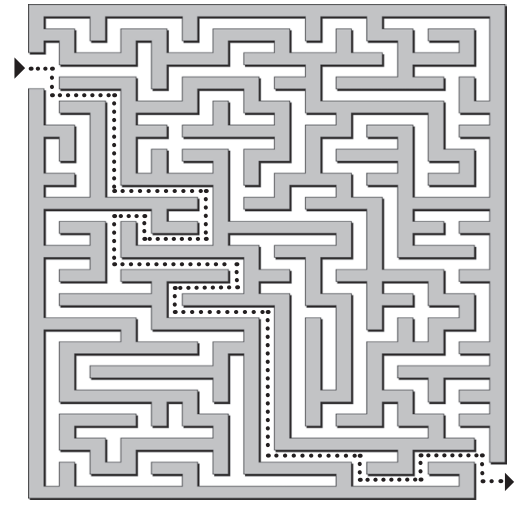

Examples from Singapore 
This page intentionally left blank 


\section{Behavioural Economics and Policy Design}

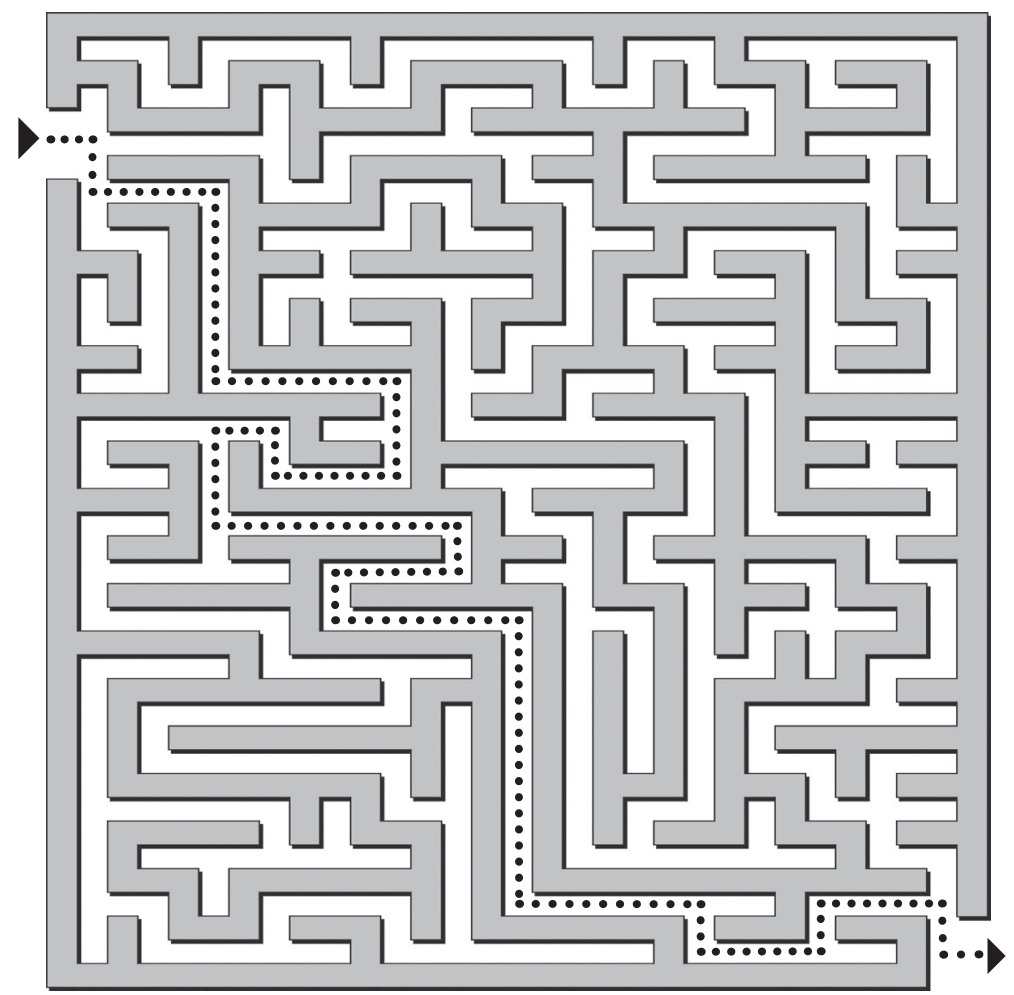

\section{Examples from Singapore}

Edited by

Donald Low 
Published by

World Scientific Publishing Co. Pte. Ltd.

5 Toh Tuck Link, Singapore 596224

USA office: 27 Warren Street, Suite 401-402, Hackensack, NJ 07601

UK office: 57 Shelton Street, Covent Garden, London WC2H 9HE

\section{Library of Congress Cataloging-in-Publication Data}

Behavioural economics and policy design : examples from Singapore / edited by Donald Low.

p. $\mathrm{cm}$.

Includes bibliographical references and index.

ISBN-13: 978-9814366007

ISBN-10: 9814366005

1. Singapore--Economic policy--Case studies. 2. Economics--Psychological aspects--

Case studies. I. Low, Donald, 1973- II. Civil Service College, Singapore.

HC445.8.B45 2011

330.01 '9--dc23

2011038079

\section{British Library Cataloguing-in-Publication Data}

A catalogue record for this book is available from the British Library.

Copyright (C) 2012 by Civil Service College, Singapore.

All rights reserved. This book, or parts thereof, may not be reproduced in any form or by any means, electronic or mechanical, including photocopying, recording or any information storage and retrieval system now known or to be invented, without written permission from the Civil Service College, Singapore. 31 North Buona Vista Road, Singapore 275983.

ISBN-13 978-981-4366-00-7

ISBN-10 981-4366-00-5

In-house Editor: Agnes Ng

Typeset by Stallion Press

Email: enquiries@stallionpress.com

Printed in Singapore. 
"Academics place much more importance on rigorous logic. There is also admiration in the profession for subtle reasoning. And mastery of the craft shows itself in the elegance of the intellectual super-structure... The practitioner, on the other hand, uses economic theory only to the extent that he finds it useful in comprehending the problem at hand, so that practical courses of action will emerge which can be evaluated not merely in narrow economic cost-benefit terms, but by taking into account a wider range of considerations.... A practitioner is not judged by the rigour of his logic or by the elegance of his presentation. He is judged by results."

Goh Keng Swee

"The world is better served by syncretic economists and policymakers who
can hold multiple ideas in their heads than by 'one-handed' economists
who promote one big idea regardless of context."

Dani Rodrik 
This page intentionally left blank 


\section{FOREWORD}

Recent events suggest that we are living in an era of increased turbulence. Take for example the wide-ranging impacts of the 1998 Asian financial crisis, the terrorist attacks of September 11, the Severe Acute Respiratory Syndrome (SARS) epidemic in 2003 and the 2008/2009 credit crisis. The common thread running across each of these crises is that they were all not foreseen sufficiently early. Yet it was not the lack of information or the absence of early warning signs that caused governments and businesses to mostly ignore the risks of an impending crisis. Indeed, the crises were predictable, or at least, they should have been better anticipated. So why weren't they?

The research that has emerged from complex systems suggests that much of our failure to have anticipated these and other lowprobability, high-impact events has to do with the way we perceive and analyse the world. The standard approaches we use to assess risks are usually based on linear causal relationships, derived from past experience. These approaches assume - implicitly — that the world is governed by definite and repeatable cause-and-effect relationships. They fail to take into account the external reality of complexity and inherent unpredictability, which suggests that many of the problems we face cannot be reduced to simple and precise cause-and-effect relationships. The weather, the economy and the natural world are examples of complex systems. Such systems exhibit regularity without being entirely predictable. They are capable of producing entirely new and unexpected forms of behaviour. In complex systems, the relationship between cause and effect is not as consistent as in the regular, simple systems we are familiar in dealing with. 
At the same time, the research from cognitive psychology and behavioural economics suggests that the standard economic approaches we are familiar with also fail to account for people's internal limitations in handling probabilities and in managing risk and uncertainty. Conventional economics, for instance, starts with the assumption that people are rational agents capable of maximising their interests and of calculating the pros and cons of their decisions in a cool and dispassionate way. The reality - as behavioural economists and cognitive psychologists have discovered - is far more complicated.

In recent years, behavioural economists have begun to apply Plato's idea that human beings have two distinct decision-making systems. When confronted with situations that require us to make decisions in a short span of time, we think in ways that are quite different than if we are given more time to make up our minds. We use the Automatic System to deal with matters that require quick decisions. The Automatic System, as the name suggests, is intuitive, unconscious (in that we make decisions even without knowing that we are making them), uncontrolled, effortless, habitual, and based on practice skills. This is the system of thinking we use in our day-to-day activities and when we have only a short time to make decisions.

When we have sufficient time for reflection and to process the information presented to us, we rely more on the Reflective System. This mode of thinking is controlled, slow, deliberate, conscious and effortful. Most of what we are taught in schools, our reasoning and analytical skills, as well as the scientific method, is based on the Reflective System. The economics that we were taught in schools and universities is also based on the assumption of rational consumers and firms making decisions using the Reflective System.

How different are these two systems of thought? Consider and answer this question as quickly as you can:

The combined cost of a ball and a bat is $\$ 1.10$ and the bat costs $\$ 1$ more than the ball. What is the price of the ball? 
If you answered ten cents, do not be surprised. The large majority of people who have taken this test also answered "ten cents". That is the result of the Automatic System. It takes a deliberate effort to override this automatic response. If you had more time to answer the question, your Reflective System would have arrived at the correct answer of five cents.

The problem is not that we have two systems of thinking and decision making. The problem arises when we rely on one system in situations when we should be using the other system. For example, if you are faced with a decision that requires you to assess risks and probabilities - such as which health insurance plan you should purchase - you ought to rely on your Reflective System. Relying on your instincts to deal with a problem which you are not familiar and have little prior experience with will probably result in poor decisions.

There are other occasions when our decisions deviate from what rational choice models in standard economics prescribe. A well known finding from behavioural economics is that people value losses more heavily than gains of the same size. Thus they value more highly a programme that restores a loss than one which provides them a gain of the same size. Similarly, they cite a much higher price to give up something they already possess as compared to the price which they are prepared to pay for exactly the same thing that they do not have.

Why do these deviations from standard economics matter for policymakers? There are at least two levels in which policymakers should take the insights of behavioural economics seriously. At one level, policymakers should appreciate the various ways in which people make decisions that depart - predictably and regularly - from the strict tenets of rationality. Behavioural economists have documented a number of cognitive biases and mental traits that can skew people's judgements of probability and uncertainty. For instance, procrastination, laziness or unfamiliarity with alternatives often lead to people having a strong bias in favour of the status quo in their choice of investment or savings plan. Knowing this, social security policymakers should think 
carefully about the defaults that are assigned to citizens, since it is quite likely that the average citizen will stick with whatever choice is set for him.

Behavioural economists have also found that people have a general inclination to judge things relative to some arbitrary reference point - this is known as the anchoring bias. For example, if a person is exposed to a high number just before he makes a purchase, he tends to be willing to pay a higher price than if he were subject to a low number, even if the number has nothing to do with the object being considered for purchase. How problems or options are framed to citizens can also have an important bearing on people's responses. People are more likely to accept a programme that has a $90 \%$ success rate than one which has a $10 \%$ failure rate, even though both statements carry identical information. Policymakers should be conscious of how citizens' responses can be altered sometimes quite significantly — by different ways in which information or choices are presented to them.

At this level of analysis, behavioural economics can help policymakers structure choices and information for their citizens in ways that take into account their cognitive biases and complications. By offering governments a more realistic understanding of how people decide under conditions of risk, uncertainty and complexity, behavioural economics provides governments with the means to design policies that are sensitive to people's psychology.

At another level, behavioural economics can also help governments to be more self-aware and to assess the risks they face more rigorously. The same cognitive biases that behavioural economists say ordinary citizens are affected by may also apply to policymakers and decision-makers in government. For instance, just as the average citizen may get anchored on a certain argument or number, so too may policymakers cling to their prevailing assumptions by mistakenly interpreting any evidence as supportive even if it is actually contradictory. This tendency to rationalise things in terms we are familiar or comfortable with can lead to governments (or other organisations) being blindsided by risks or problems that they have not contemplated before. The failure of most mainstream 
economists to anticipate the financial crisis of 2008 is a case in point. Most of them did not question the prevailing wisdom of the times - that we were living in an era of the Great Moderation (low inflation, sustained growth), that central banks had figured out how to stabilise the economy, and that financial innovation had diversified and reduced risks - and were therefore caught out by the crisis.

Related to this is the tendency of the human mind to see what it wants to see and to ignore evidence that contradicts its beliefs. This confirmation bias, combined with over-confidence (another mental trait that behavioural economists have identified), can lead to hubris and the inability to imagine that something very bad could happen - a phenomenon known as "disaster myopia". Disaster myopia afflicts organisations as much as it does individuals. The lesson for governments in all this is to remember the motto of Delphi - "Know Thyself" — and to understand the role that emotions and cognitive biases play in our decision-making processes.

This book is a valuable contribution to the discussion on how behavioural economics can help governments do better — both in terms of designing policies that accommodate people's cognitive biases as well as being conscious of their own. Good ideas in public policy are not developed in the laboratory. They must take into account how the ideas are translated into implementable, enforceable and accepted policies. Singapore's experience is useful in this regard. As many of the chapters here attest, there was a conscious effort on the part of Singapore's policymakers to incorporate people's likely responses and reactions into the design of policies. Even when policies are grounded in sound economic logic, there is no guarantee that they will be widely accepted. Often, they have to be tweaked, adjusted or significantly reframed to ensure public acceptance. The combination of standard economic principles and insights from behavioural economics is an important contributing factor to sound public policies in Singapore.

Having encouraged the Civil Service College, Singapore to expand its repertoire of programmes to include behavioural economics and its applications in public policy, I am heartened to see 
the publication of this book. I am also thankful that my colleagues in the civil service have made a great effort to bring these examples of complex policy formulation into the public domain. Their effort is worthwhile as it will bring about a greater appreciation of the value of behavioural economics in public administration. The book will be an important source of cases for the teaching of behavioural economics at the college. It will also provide ideas on how behavioural economics and, more generally, insights from the cognitive sciences can be of value to governments. Finally, I hope the book will encourage readers to reflect on how public policies can be improved and refined as we understand human behaviour better.

Lam Chuan Leong

Ambassador-at-large Ministry of Foreign Affairs

and

Senior Fellow Civil Service College, Singapore 


\section{ACKNOWLedgements}

This book would not have been possible without a great deal of help from many people. I would like to record my thanks to all the contributors from the Singapore government who took time to write in their personal capacity. Not only did they take up the challenge of writing about a relatively unexplored subject, they also had to put up with my incessant questions and numerous revisions to their drafts. Wendy Wong of the Civil Service College, Singapore and Cheryl Chung of the Ministry of Trade and Industry painstakingly conceptualised and developed the illustrations in this book. I am grateful for their patience and hard work.

I owe a huge debt of gratitude to two individuals. The first is Professor Jack Knetsch, Emeritus Professor of Economics at Simon Fraser University. Professor Knetsch is one of the pioneers in behavioural economics. As a Senior Visiting Fellow of the Civil Service College, he helped to establish the college's training and research programmes in behavioural economics and public policy. He provided wise counsel throughout the entire journey of this book - from its conceptualisation, to the identification of chapters, to providing specific ideas on how each of them could be made more credible and persuasive. The second individual is Dawn Yip who tirelessly read through early drafts of the chapters and provided valuable editorial and content inputs.

I would also like to thank my former colleagues at the Civil Service College. The former and current deans of the college Chan Heng Kee and Lionel Yeo respectively - encouraged me to advance economics literacy in the Singapore public service. My colleagues - especially Tan Li San, Chng Kai Fong, Low Chee Seng, Wu Wei Neng, Sharon Tham, Christian Chao, Andrew Kwok, 
Gabriel Wong, Pamela Qiu and Song Hsi Ching — provided ideas and a listening ear. The fellows at the college's Centre for Public Economics — David Skilling, Manu Bhaskaran, Yeoh Lam Keong and Lawrence Wong - were also extremely generous with their time and advice.

Outside of the college, I had the privilege of working with some of the best minds in the Singapore public service: Lim Siong Guan, Peter Ho, Ravi Menon, Lam Chuan Leong, Yong Ying-I, Chan Lai Fung, Philip Ong, Lai Wei Lin, Tai Wei Shyong, Chia Der Jiun, Francis Chong, Edward Robinson, Lee Kok Fatt, Dominic Soon, Devadas Krishnadas, Koh Tsin Yen, Keith Tan, Thia Jang Ping, Yip Chun Seng, Jeffrey Siow, Neo Bee Leng, Amanda Chua, Valerie Yuen, Godwin Tang, Bernard Toh, Sheila Pakir, Jeanette Kwek and Liu Feng-yuan. They gave me plenty of food for thought and abundant opportunities for intellectual sparring - not just for this book, but also in many other aspects of public policy. Sam Lam and Alan Sim at Linkage Asia encouraged me to bring the ideas of behavioural economics to audiences outside of the government, while Professors Neo Boon Siong and Henri Ghesquiere - the authors of two excellent books on the Singapore government - gave valuable suggestions on what policymakers elsewhere and students of government might find useful about Singapore's experience.

From my former perch at the Centre for Public Economics, I also had the privilege of engaging with some of the world's most creative economists and policy intellectuals: Paul Romer, Robert Frank, Ed Lazear, Arvind Subramaniam, Andrew Sheng, Bryan Caplan, Kenneth Lieberthal, Huang Yasheng, Linda Lim, Dani Rodrik, John Cassidy and Anatole Kaletsky. They provided thought-provoking insights and challenged my own assumptions and biases. 


\section{Contents}

FOREWORD vii

ACKNOWLEDGEMENTS Xiii

Aвоuт тHе Althors $\quad$ xvii

INTRODUCTION

Cognition, Choice and Policy Design

Donald LOW

PART I

Chapter 1 Key Ideas in Behavioural Economics -

And What They Mean for Policy Design $\mathrm{KOH}$ Tsin Yen

Chapter 2 Incentives, Norms And Public Policy

Charmaine TAN and Donald LOW

\section{PART II}

Chapter 3 A Behavioural Perspective to Managing Traffic CONGESTION IN SINGAPORE LEONG Wai Yan and LEW Yii Der

Chapter 4 Can Psychology Save the Planet and Improve OUR ENVIRONMENT?

Philip ONG

Chapter 5 Promoting Competition in Electricity Retail:

INSIGHTS FROM BEHAVIOURAL ECONOMICS

Eugene TOH and Vivienne LOW 
xvi Contents

Chapter 6 Discretionary Transfers: Providing Fiscal Support in a Behaviourally Compatible Way Pamela QIU and TAN Li San

Chapter 7 Using Behavioural Insights to Improve INDIVIDUAL HeALTh DeCisions Lavinia LOW and YEE Yiling

Chapter 8 A Behavioural View on Designing Singapore's National AnNuity Scheme Donald LOW

Chapter 9 Behavioural Economics, Policy Analysis and the Design of Regulatory Reform Jack KNETSCH

INDEX 


\section{About the Authors}

Jack KNETSCH is Emeritus Professor of Economics at Simon Fraser University and has held recent appointments as a Senior Visiting Fellow at the Civil Service College, Singapore and the Nanyang Visiting Professor at the Nanyang Technological University. His research on behavioural economics and applications to policy issues, extending over three decades, has appeared in most leading international journals. His name continues to appear regularly on lists of the most cited economists.

KOH Tsin Yen heads the Social Strategy Unit at the Ministry of Finance (MOF), Singapore, which studies medium-term social trends and issues and identifies gaps in the provision of social services. She has worked on a range of social policy and research issues in MOF and the Civil Service College, including subsidies for public housing and public education, assistance schemes for lowerincome households, and changes to the social security system in Singapore.

LEONG Wai Yan served as a senior economist with the Policy and Planning Group of the Land Transport Authority (LTA), Singapore from 2008 to 2010 . While at the LTA, he researched a wide array of land transport issues, such as cost-benefit analyses of rail projects and the impact of congestion pricing on motorists' behaviour. He has contributed substantively in the area of stated preference surveys and discrete choice modelling, including the updating 
of key economic parameters such as willingness-to-pay measures. In the course of his work, he developed a keen interest in behavioural economics and its applications to land transport policies. Mr. Leong holds a first class honours degree in Economics from Princeton University and a Masters in Economics from Stanford University. He is currently pursuing his $\mathrm{PhD}$ at the University of Sydney.

LEW Yii Der is the Group Director of the Policy and Planning Group of the Land Transport Authority (LTA), Singapore. His current portfolio includes studying reforms to the public transport industry structure and expanding the research and training capacity of the LTA Academy. Yii Der has been with the LTA since its formation in 1995 and has held various management positions. He holds a first class honours degree in Civil Engineering from the National University of Singapore and a Masters in Public Management from the Lee Kuan Yew School of Public Policy.

Donald LOW helped to establish the Centre for Public Economics at the Civil Service College, Singapore in 2009 and served as its first head for two years. The centre's role is to advance economics literacy in the Singapore public service through its training, outreach and research programmes. Prior to joining the college, he served in various capacities in the Singapore government. He was formerly the Director of Fiscal Policy at the Ministry of Finance, as well as the Director of the Strategic Policy Office in the Public Service Division. He is currently a vice president at the Economics Society of Singapore. Donald holds a first class honours degree in Politics, Philosophy and Economics from Oxford and a Masters in International Public Policy from Johns Hopkins University's School of Advanced International Studies.

Lavinia LOW is Assistant Director in Finance Policy at the Ministry of Health, Singapore. Her work includes policy development for MediShield (a basic catastrophic illness insurance scheme), the regulation of Medisave-approved insurance schemes, as well as the 
administration and regulation of ElderShield (a basic severe disability insurance scheme) and its supplementary plans.

Vivienne LOW is an analyst from the Policy and Planning Department of the Energy Market Authority, Singapore. She graduated from the National University of Singapore with a degree in Economics. She is currently responsible for the analysis of global trends and developments in energy, as well as the formulation of policies and strategies to facilitate the development of smart grids in Singapore.

Philip ONG is Director, Environmental Policy at the Ministry of Environment and Water Resources, Singapore. He is responsible for the review and formulation of policies on resource efficiency and environmental protection to support public health, sustainable development and a better quality of life. He joined the Ministry in 2008, initially covering climate change and energy efficiency issues, before overseeing environmental policies in 2009.

Pamela QIU joined the Centre for Public Economics at the Civil Service College, Singapore as a researcher from 2009 to 2011. Her areas of research included the economics of privatisation, regulation and competition policy, as well as fiscal management and social spending. From 2007 to 2009, she was an associate (Social Strategy) at the Ministry of Finance (MOF) where she worked on developing long-term strategies to improve the social services sector. The issues she worked closely on while at MOF included human capital development, reducing under-employment and facilitating social entrepreneurship.

Charmaine TAN is currently a research associate at the Centre for Public Economics at the Civil Service College, Singapore. Her research interests include the economics of industrial organization, regulation, competition policy and behavioural economics. She graduated with a BSc (Hons) in Economics from the National University of Singapore and a Masters in Economics of Markets 
and Organisations (Research) from the Toulouse School of Economics.

TAN Li San is Director of the Centre for Governance and Leadership at the Civil Service College, Singapore. She is concurrently Director of the Strategic Policy Office, including the Centre for Strategic Futures which helps to develop futures-planning capabilities across the Singapore public service. Li San has held various government positions during her career, including a stint at the Ministry of Finance from 2005 to 2009 where, as Director of the Social Programmes Directorate, she was responsible for the allocation of fiscal resources within the social sector.

Eugene TOH is Deputy Director of the Policy and Planning Department in the Energy Market Authority, Singapore. He graduated with a Masters in Electrical and Computer Engineering (ECE) from Carnegie Mellon University, USA and has a double first class Bachelor's degree in Economics and Philosophy, and ECE from the same institution. Prior to joining the Energy Planning and Development Division, he specialised in the regulation of competitive energy markets as Deputy Director of the EMA's Market Development and Surveillance Department. He is also concurrently the Deputy Project Director of the Intelligent Energy System pilot project, an initiative to develop the smart grid infrastructure and its applications for potential deployment in Singapore.

YEE Yiling is a health policy analyst in Finance Policy at the Ministry of Health, Singapore. Her work includes the administration and regulation of ElderShield and its supplementary plans, as well as the study of micro and macroeconomic perspectives of healthcare financing issues. 